\title{
Long-term estimation of soil heat flux by single layer soil temperature
}

\author{
Cheng-I Hsieh • Cheng-Wei Huang • Ger Kiely
}

Received: 24 June 2008 / Revised: 10 November 2008 /Accepted: 10 November 2008 / Published online: 2 December 2008

(C) ISB 2008

\begin{abstract}
Soil heat flux is one of the important components of surface energy balance. In this study, long-term estimation of soil heat flux from single layer soil temperature was carried out by the traditional sinusoidal analytical method and the half-order time derivative method of Wang and Bras [Wang and Bras (1999) J Hydrol 216:214-226]. In order to understand the characteristics of soil heat flux and to examine the performances of the two methods, a field experiment was conducted at a temperate and humid grassland in Cork, Ireland. Our results show that the soil heat flux had the same magnitude as the sensible heat flux at this grassland site. It was also demonstrated that the analytical method did not predict the soil heat flux well because the sinusoidal assumption for the temporal variation in soil heat flux was invalid. In contrast, good agreement was found between the soil heat flux measurements and predictions made by the half-order time derivative method. This success suggests that this method could be used to estimate soil heat flux from long-term remotely sensed surface temperature.
\end{abstract}

Keywords Half-order method · Soil heat flux . Soil temperature

C.-I. Hsieh $(\bowtie) \cdot$ C.-W. Huang

Department of Bioenvironmental Systems Engineering,

National Taiwan University,

Taipei 10617, Taiwan

e-mail: hsieh@ntu.edu.tw

G. Kiely

Department of Civil and Environmental Engineering,

University College Cork,

Cork, Ireland

\section{Introduction}

Soil heat flux (or ground heat flux) plays an important role in surface energy balance at the land-atmosphere interface, and in meteorological modelling. On a well-watered and full-vegetation-covered surface, the soil heat flux is of the same order as the sensible heat flux (Kustas and Daughtry 1990; Clothier et al., 1986). For dry soil surfaces, the soil heat flux could be up to $50 \%$ of the net radiation (Idso et al. 1975). Even within a forest, the soil heat flux represents $30-50 \%$ of the net radiation over the understory (Ogee et al. 2001).

Direct soil heat flux measurements can be carried out using a soil heat flux plate, but the plate needs to be installed at a certain depth in the soil. Hence, a temperature measurement is still needed for calculating the heat storage at this depth of soil. Many methods (e.g. Kimball and Jackson 1975; Stull 1988; Malek 1993) have been developed to calculate soil heat flux; however, most of them need the soil temperature measured in at least at two layers, which is inconvenient for large area monitoring. Assuming the surface temperature varies sinusoidally, an analytical solution of the one-dimensional heat diffusion equation for calculating soil heat flux from one level of soil temperature measurement is available. However, this analytical solution may not reflect the real soil environment very well due to this assumption of sinusoidal temperature variation (Campbell and Norman 1998). Wang and Bras (1999) proposed a half-order time derivative method to solve the heat diffusion equation and to calculate soil heat flux. The advantage of this method is that it requires only one layer of soil temperature time series observations. Wang and Bras (1999) verified their method with two types of data. The first data set was generated by numerically solving a complete set of nonlinear equations of coupled 
heat and water transfer in a one-dimensional soil column. The second data set was from observations (of 10-12 days duration) of two field experiments: the First ISLSCP Field Experiment (FIFE) project, and the Anglo-Brazilian Amazonian Climate Observation Study (ABRACOS) project (see Wang and Bras 1999). However, this method has not yet been tested for long-term calculation of soil heat flux and compared with the analytical solution.

As soil heat flux represents an important surface energy component, a method yielding the most accurate calculation with the least difficulty is required, especially for long-term studies. Single layer (or surface layer) time series measurements of soil temperature are much easier to obtain in-situ or remotely than vertical distributions of soil temperature. Hence, the objectives of this study were ((1) to evaluate the performances of two single-layer methods - the traditional sinusoidal analytical method (Carslaw and Jaeger 1986), and the half-order time derivative method of Wang and Bras (1999) - in estimating soil heat flux for long-term studies; and (2) to study the characteristics of soil heat flux at a grassland site. For the purposes of this study, an in-situ experiment was carried out at a temperate and humid grassland near Cork in Ireland. This experiment provides, from a real environmental scenario, the long-term and continuous field observations required to assess the capability of the two methods for estimating soil heat flux.

\section{Materials and methods}

\section{Analytical methods}

The traditional sinusoidal analytical method and the halforder time derivative method of Wang and Bras (1999) for estimating soil heat flux from a single-layer soil temperature time series measurement are described in the following sections.

\section{Traditional sinusoidal analytical method}

The one-dimensional heat diffusion equation for heat transport in the soil can be written as

$\rho_{s} c_{s} \frac{\partial T}{\partial t}=-\frac{\partial G}{\partial z}$,

where $t$ is time, $z$ is the depth below the surface, $T$ is the soil temperature, $G\left(\mathrm{~W} \mathrm{~m}^{-2}\right)$ is the soil heat flux, $\rho_{s}\left(\mathrm{~kg} \mathrm{~m}^{-3}\right)$ is the soil density, and $c_{S}\left(\mathrm{~J} \mathrm{~kg}^{-1} \mathrm{~K}^{-1}\right)$ is the soil specific heat; while $\rho_{s} \mathrm{C}_{s}\left(\mathrm{~J} \mathrm{~m}^{-3} \mathrm{~K}^{-1}\right)$ represents the volumetric heat capacity. Combining equation (1a) and Fourier's law for heat transport,

$G=-k \frac{d T}{d z}$, gives

$\rho_{s} c_{s} \frac{\partial T}{\partial t}=\frac{\partial}{\partial z}\left(k \frac{\partial T}{\partial z}\right)$,

where $k\left(\mathrm{~W} \mathrm{~m}^{-1} \mathrm{~K}^{-1}\right)$ is the thermal conductivity. Assuming the soil properties are uniform over the entire soil profile and the soil surface temperature varies sinusoidally (Carslaw and Jaegr 1986), the analytical solution of Eq. (2) for calculating the soil temperature at any depth and time is

$$
\begin{aligned}
T(z, t)= & T_{\text {ave }}+A(0) \exp (-z / D) \\
& \times \sin \left[\omega\left(t-t_{0}\right)-z / D\right],
\end{aligned}
$$

where $T_{\text {ave }}\left({ }^{\circ} \mathrm{C}\right)$ is the average surface temperature over a cycle, $A(0)\left({ }^{\circ} \mathrm{C}\right)$ is the amplitude of the soil temperature fluctuations, and $t_{0}(\mathrm{~s})$ is the phase shift. In Eq. 3, $\omega\left(\mathrm{sec}^{-1}\right)$ and $D(\mathrm{~m})$ are the angular frequency and damping depth, respectively, and are defined as:

$\omega=\frac{2 \pi}{\tau} ; D=\sqrt{\frac{2 D_{0}}{\omega}}$

where $\tau$ is the period of the temperature fluctuations and $D_{0}=\mathrm{k} /\left(\rho_{\mathrm{s}} \mathrm{C}_{\mathrm{s}}\right)\left(\mathrm{m}^{2} \mathrm{~s}^{-1}\right)$ is the thermal diffusivity.

Considering Eq. 1b, and differentiating Eq. 3 with respect to $z$, the analytical solution for soil heat flux at any depth and time is

$$
\begin{aligned}
\mathrm{G}(z, t)= & \frac{\sqrt{2} A(0) k}{D} \exp \left(-\frac{z}{D}\right) \\
& \times \sin \left[\omega\left(t-t_{0}\right)-\frac{z}{D}+\frac{\pi}{4}\right]
\end{aligned}
$$

Applying Eq. 5 and set $z=0$, the surface soil heat flux can be computed as:

$G(0, t)=\frac{\sqrt{2} A(0) k\left[\sin \left[\omega\left(t-t_{0}\right)\right]+\pi / 4\right]}{D}$

Equation 5 indicates that soil heat flux also varies sinusoidally with time and its mean equals zero, which implies that the total soil heat flux received from the sun during daytime is released from the deeper soil back to the atmosphere during the night. When applying this analytical solution for estimating soil heat flux, only one single-layer time series data of soil temperature is needed. The beauty of this analytical solution is that once the amplitude of the temperature fluctuations is determined from any depth of the soil temperature measurement, the soil heat flux at any depth can be readily calculated by Eq. 5 .

\section{Half-order time derivative method}

Assuming a constant thermal diffusivity, $D_{0}$, Eq. 2 can be rewritten as

$\frac{\partial T}{\partial t}=D_{0} \frac{\partial^{2} T}{\partial z^{2}}$. 
For solving the differential Eq. 7 to estimate the soil heat flux, a knowledge of the initial and boundary conditions is necessary. Note that the variation in soil temperature far below the ground surface is near zero; and the initial soil temperature profile is uniform throughout the entire soil layer. Therefore, the initial and boundary conditions for the soil temperature can be given as:

$T=T_{0}$, for $t=0, \quad z \leq 0$

$T=T_{0}$, for $t>0, z \rightarrow-\infty$

where $T_{0}$ is the initial temperature. Equation 8 states that the initial soil temperatures through every soil layer are the same, and requires that the computation of soil heat flux be started at the time when the soil heat flux is zero.

Based on Eqs. 7-9 and the half-order time derivative, Wang and Bras (1999) derived the statement that the vertical gradient of temperature can be a function of the weighted average of a soil temperature time series, and the soil heat flux, $G$, at any depth and time can be calculated by the soil temperature as:

$G(z, t)=\sqrt{\frac{k \rho_{s} c_{s}}{\pi}} \int_{0}^{t} \frac{d T(z, s)}{\sqrt{t-s}}$

where $s$ is the integration variable. Equation 10 is the socalled half-order time derivative method for estimating soil heat flux. A detailed derivation of Eq. 10 is provided in the Appendix. The advantage of Eq. 10 is that only single-layer time series data of soil temperature at a certain depth and the soil property information are required for estimating the soil heat flux at that same depth. The small disadvantage of using Eq. 10 to estimate soil heat flux is that the integration must start from a time when the ground heat flux is near zero as required by Eq. 8. Practically speaking, the starting time of the integration can be set at midnight, as the soil heat flux is small or around zero at that time.

\section{Experiment}

The experiment was conducted at a temperate and humid grassland in County Cork in Eire (southern Ireland; latitude: $52.14^{\circ} \mathrm{N}$, longitude: $8.66^{\circ} \mathrm{W}$ ) throughout the entire year of 2002. In this experimental site, the grassland type was pasture and meadow and the dominant plant species was perennial ryegrass. The grass height varied from 0.1 to $0.45 \mathrm{~m}$ during the experiment. The soil type is sandy loam and the soil properties are summarised in Table 1.

Two soil heat flux plates were installed at a depth of 5 $\mathrm{cm}$ from the soil surface to measure the soil heat flux. Also, two soil temperature probes were buried at a depth of $5 \mathrm{~cm}$ to measure the soil temperature and heat storage at this soil
Table 1 Summary of the properties. The mean damping depth was determined by Eq. 4

\begin{tabular}{ll}
\hline Soil properties & \\
\hline Bulk density $\left(\mathrm{g} \mathrm{cm}^{-3}\right)$ & 1.3 \\
Porosity & 0.61 \\
Mean thermal conductivity $\left(\mathrm{W} \mathrm{m}^{-1} \mathrm{~K}^{-1}\right)$ & 1.07 \\
Soil moisture content $($ volumetric) & $0.22-0.61$ \\
Volumetric heat capacity $\left(\mathrm{MJ} \mathrm{m}^{-3} \mathrm{~K}^{-1}\right)$ & $1.84-3.47$ \\
Thermal diffusivity $\left(\mathrm{m}^{2} \mathrm{~s}^{-1}\right)$ & $3.1 \times 10^{-7}-5.81 \times 10^{-7}$ \\
Mean damping depth $(\mathrm{m})$ & 1.48
\end{tabular}

depth. The soil heat flux at the soil surface, $G(0, t)$, was then calculated as

$$
\begin{aligned}
G(0, t) & =G(0.05, t)+\Delta G \\
& =G(0.05, t)+\rho_{s} c_{s} \frac{\partial T}{\partial t} \Delta z
\end{aligned}
$$

where $G(0.05, t)$ is the soil heat flux measured by the soil heat flux plate installed at $5 \mathrm{~cm} ; \Delta G$ is the heat stored within this 5 -cm-thick soil layer, which is calculated from the soil temperature time series measured at $5 \mathrm{~cm}$; and $\Delta z$ $(=0.05 \mathrm{~m})$ is the thickness of the soil layer above the heat flux plate. Note that if the skin temperature is measured, then Eq. 10 could provide a semi-direct estimate of surface soil heat flux. A soil moisture sensor was also used to measure the volumetric soil moisture content at $5 \mathrm{~cm}$ depth. The air temperature at $3 \mathrm{~m}$ was also measured.

In addition to soil heat flux measurements, an eddycovariance system consisting of a three-dimensional sonic anemometer (model 81000; R.M. Young,Traverse City, MI) and an open-path $\mathrm{CO}_{2} / \mathrm{H}_{2} \mathrm{O}$ infrared gas analyzer (LI7500, Li-Cor, Lincoln, NE) was used to measure sensible heat, latent heat, and $\mathrm{CO}_{2}$ fluxes. A net radiometer was installed for measuring net radiation. The sonic anemometer, gas analyzer, and net radiometer were all positioned at $10 \mathrm{~m}$ height from the soil surface. All raw data, measured and averaged at $10 \mathrm{~Hz}$ and $30 \mathrm{~min}$, respectively, were collected with a data-logger and then transmitted to a computer.

When applying the traditional sinusoidal analytical and the half-order time derivative methods to estimate soil heat flux, the soil volumetric heat capacity, $\rho_{\mathrm{s}} \mathrm{C}_{\mathrm{s}}$, and thermal conductivity, $\mathrm{k}$, are needed. At this site, the mean soil thermal conductivity was $1.07\left(\mathrm{~W} \mathrm{~m}^{-1} \mathrm{~K}^{-1}\right)$; while the soil volumetric heat capacity was computed as the sum of the heat capacities of the dry soil and soil water (Zhang et al. 2007):

$\rho_{s} c_{s}=(1-\phi) \rho_{m} c_{m}+\theta \rho_{w} c_{w}$

where $\varphi$ is the soil porosity, $\theta\left(\mathrm{m}^{3} \mathrm{~m}^{-3}\right)$ is the volumetric water content, $\rho_{\mathrm{m}}$ is the density of dry mineral soil $\left(\mathrm{kg} \mathrm{m}^{-3}\right)$, $\rho_{\mathrm{w}}\left(\mathrm{kg} \mathrm{m}^{-3}\right)$ is the water density, and $\mathrm{c}_{\mathrm{m}}\left(\mathrm{J} \mathrm{kg}^{-1} \mathrm{~K}^{-1}\right)$ and $c_{\mathrm{w}}\left(\mathrm{J} \mathrm{kg}^{-1} \mathrm{~K}^{-1}\right)$ are the specific heat of dry mineral soil and 
water, respectively. In Eq. 12, the contribution of air is neglected. During the year 2002, the measured volumetric soil moisture $\theta$ was between 0.22 and 0.61 , and by Eq. 12 the volumetric heat capacity $\rho_{\mathrm{s}} \mathrm{C}_{\mathrm{s}}$ was found to be in the range of 1.84 to $3.47\left(\mathrm{MJ} \mathrm{m}^{-3} \mathrm{~K}^{-1}\right)$.

\section{Results and discussion}

\section{Surface energy flux characteristics}

Figure 1a shows the temporal variations in the net radiation, $R_{\mathrm{n}}$, and surface soil heat flux, $G(0, t)$, at the grassland for the whole year of 2002. It is clear that $R_{\mathrm{n}}$ varied with season and had a bell-shaped annual cycle that reached a minimum value in the winter and a maximum in the summer. Note that, in Fig. 1a, the soil heat flux also varied with season, but did not follow the same trend as $R_{\mathrm{n}}$. This can be attributed to the following. The peaks of the observed net radiation and surface soil heat flux were around day 157 and day 112, respectively. Around the peak period of net radiation, the grass was taller and the land surface was more covered by vegetation. Hence, a lower percentage of the net radiation was distributed to the soil heat flux during this peak period ( day 157), resulting in
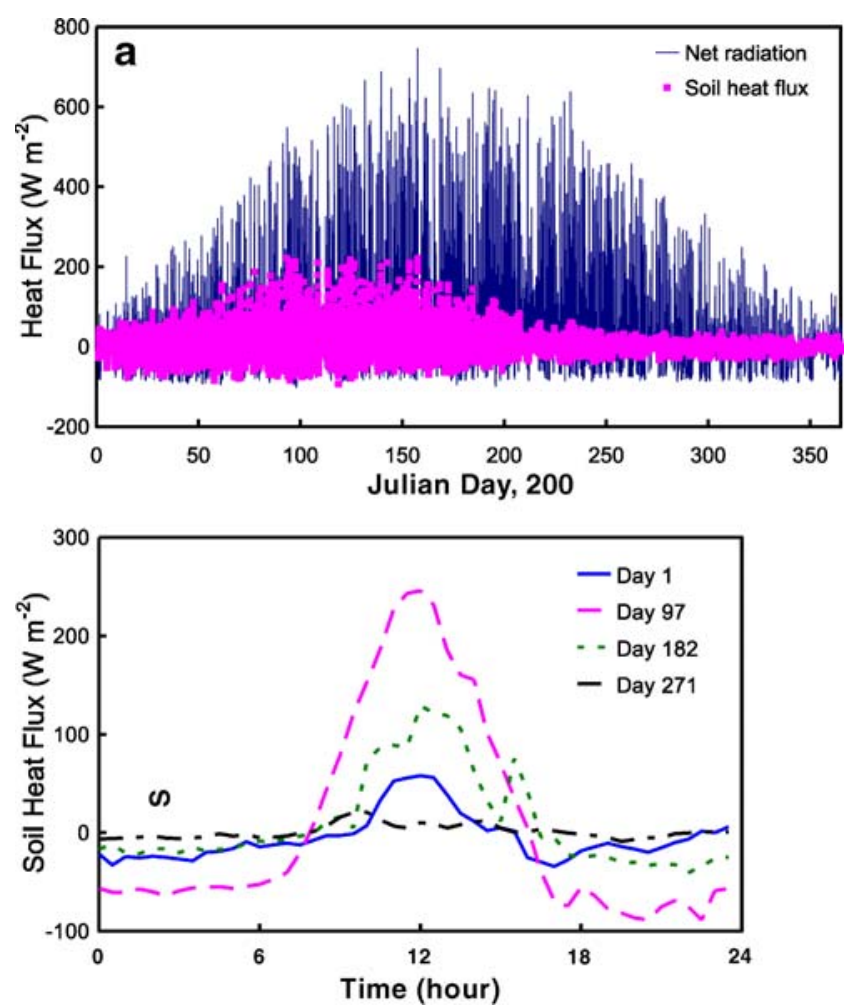

Fig. 1 a Temporal variations in net radiation and surface soil heat flux at a grassland near Cork, Eire, for the whole year of 2002. b Typical diurnal cycles of the soil heat flux in winter, spring, summer, and autumn (represented by days 1, 97, 182, and 271, respectively) the peak period of soil heat flux being shifted to an earlier time ( day 112). From autumn to winter (September to December), the soil heat flux was almost constant, and this was the minimum value within the year. Starting from January, the soil heat flux increased gradually and reached its maximum at the end of spring; it then decreased with time until the end of August. Figure 1b shows typical diurnal cycles of the soil heat flux in winter, spring, summer, and autumn (represented by days 1, 97, 182, and 271 , respectively). It is clear that these soil heat fluxes did not have the sinusoidal diurnal cycles as implied/assumed in Eq. 5. Instead, these soil heat fluxes showed the bellshaped variations that had minimum values at night and maximums around noon. Recall that the analytical solution, i.e. Eq. 5, assumes that the soil surface temperature varies sinusoidally with time. Hence, the derived soil heat flux also varies sinusoidally with time. It is common to find that measured soil heat fluxes do not follow this sinusoidal behavior. During daytime, the source of soil heat flux is from the net radiation; however, during the night the source of soil heat flux is from the deeper and warmer ground. Hence, generally speaking, daytime soil heat fluxes are larger than nighttime fluxes in terms of magnitude. One interesting point to note in Fig. $1 \mathrm{~b}$ is that the times at which the maximum heat fluxes occured in days 1,97 , and 182 were all around noon and did not shift with different seasons.

The relationship between the net radiation and sensible heat flux is shown in Fig. 2a. The solid line represents the linear regression between these two parameters. The slope of the regression line is 0.26 and the value of the coefficient of determination, $R^{2}$, is 0.73 . This shows that the sensible heat flux is strongly related to the net radiation and close to $26 \%$ of the net radiation energy was distributed to sensible heat flux. Figure $2 \mathrm{~b}$ and $\mathrm{c}$ are the same as Fig. 2a but showing water vapor flux and surface soil heat flux. These results show that about $34 \%$ and $24 \%$ of the net radiation were used for evapotranspiration and soil heat flux. Note that, from Fig. 2a to c, the energy closure for this grassland was near $85 \%$ and the soil heat flux was as large as the sensible heat flux.

\section{Traditional sinusoidal analytical method estimation}

Since the surface soil heat flux cannot be measured directly by the soil heat flux plate at the soil surface, a more direct and appropriate way for evaluating the performance of the two methods is to use the soil heat flux measured at $5 \mathrm{~cm}$, $G(0.05, t)$. With Eq. 5 and measured soil temperature at $5 \mathrm{~cm}$, we predicted the soil heat flux at this depth. Figure $3 \mathrm{a}$ shows the comparison between observed and estimated soil heat fluxes by the traditional sinusoidal analytical method (hereafter analytical method). A typical time series com- 

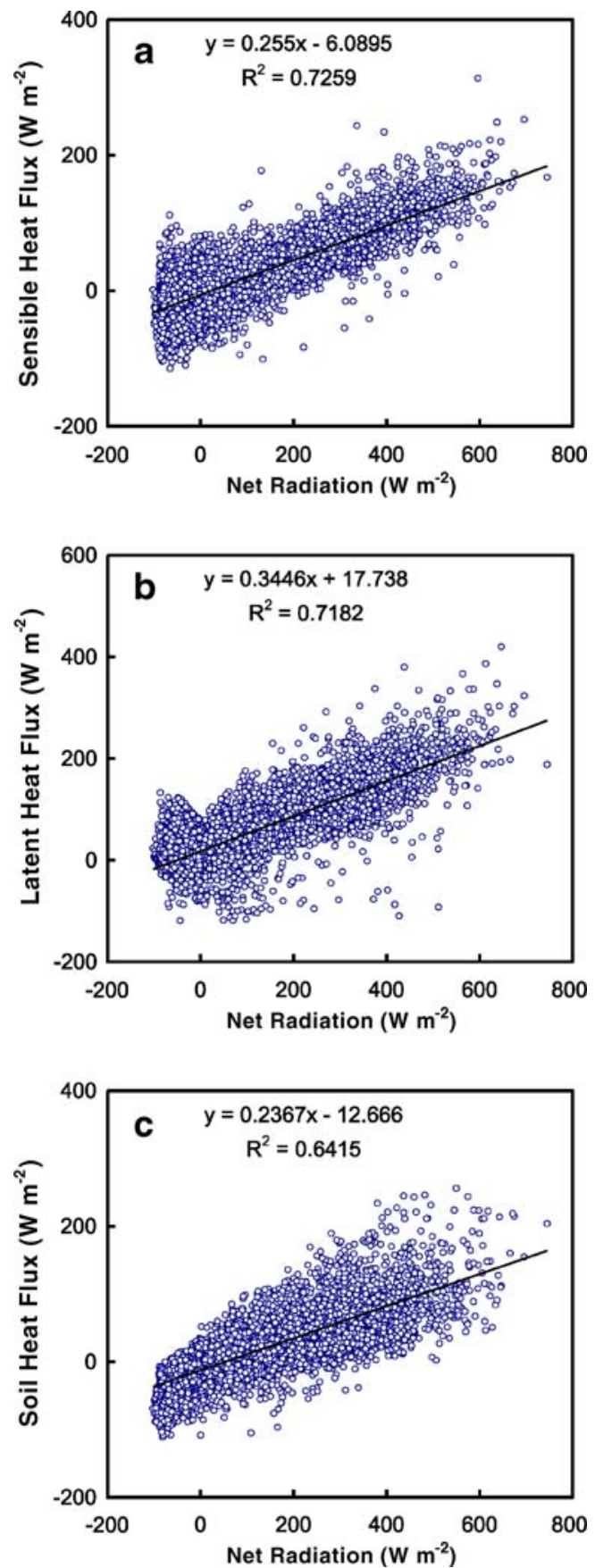

Fig. 2 Relationships between the net radiation and a sensible heat flux, b water vapor flux, and $\mathbf{c}$ surface soil heat flux. The solid line represents the linear regression between the two parameters

parison, from day 90 to 100 , is also shown in Fig. 3b. The $R^{2}$ and standard error of estimation (SEE) in Fig. 3a are 0.42 and $16.45\left(\mathrm{~W} \mathrm{~m}^{-2}\right)$, respectively (regression statistics are also summarised in Table 2). It is clear that the analytical solution did not reproduce the measured soil heat flux well. And, as shown in Fig. 3b, the soil heat flux was overestimated during the night (heat transported upward) and slightly underestimated during daytime (heat
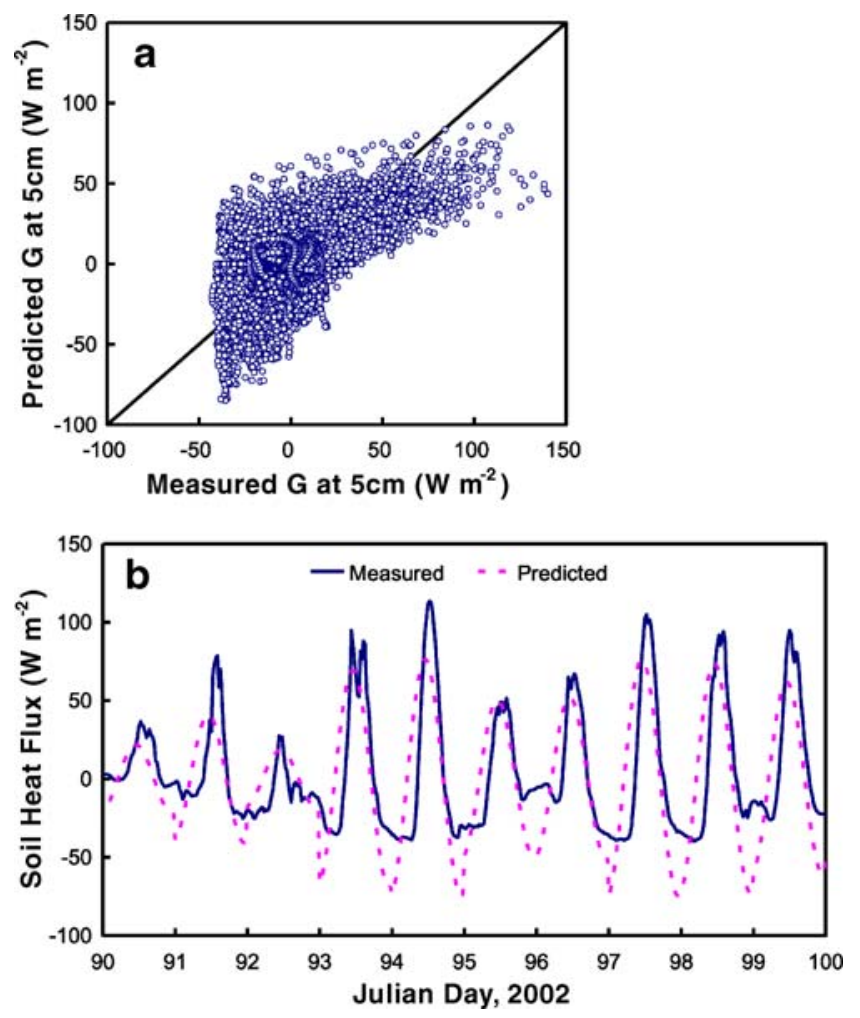

Fig. 3 Comparison between observed and estimated soil heat fluxes calculated by the traditional sinusoidal analytical method at $5 \mathrm{~cm}$. For clarity purpose, only the measurements and predictions from days 90 to 100 are plotted. a Scatter plot, $\mathbf{b}$ time series plot

transported downward). This is because the assumption that the soil temperature and heat flux vary sinusoidally with time is invalid, as demonstrated in Fig. 1b.

To further evaluate the usefulness of the analytical method, we compared the measured soil heat flux at the surface, $G_{\mathrm{m}}(0, t)$, with the predictions, $G_{\mathrm{p}}(0, t)$. Here, $G_{\mathrm{m}}$ $(0, t)$ is the sum of soil heat flux measured at $5 \mathrm{~cm}, G_{\mathrm{m}}$ $(0.05, t)$, and the heat storage in this $5 \mathrm{~cm}$ thick of soil, $\Delta G_{\mathrm{m}}(0.05, t)$; while $G_{\mathrm{p}}(0, t)$ is calculated as the sum of predicted soil heat flux at $5 \mathrm{~cm}, G_{\mathrm{p}}(0.05, t)$, and the heat storage $\Delta G_{\mathrm{m}}(0.05, t)$. The comparisons between $G_{\mathrm{m}}(0, t)$ and $G_{\mathrm{p}}(0, t)$ in scatter and time series plots are shown in Fig. $4 \mathrm{a}$ and $\mathrm{b}$, respectively. For clarity, only the measure-

Table 2 Coefficients of regression analyses between measured and estimated soil heat fluxes calculated by the traditional analytical and half-order time derivative methods. SEE Standard error of estimation

\begin{tabular}{llllll}
\hline Method & Flux & Slope & Intercept & $R^{2}$ & SEE \\
\hline Analytical & $G(0.05, t)$ & 0.64 & -0.64 & 0.42 & 16.45 \\
& $G(0, t)$ & 0.87 & -0.86 & 0.76 & 16.45 \\
Half-order & $G(0.05, t)$ & 0.96 & 2.50 & 0.94 & 5.40 \\
& $G(0, t)$ & 1.00 & 2.46 & 0.98 & 5.40 \\
\hline
\end{tabular}



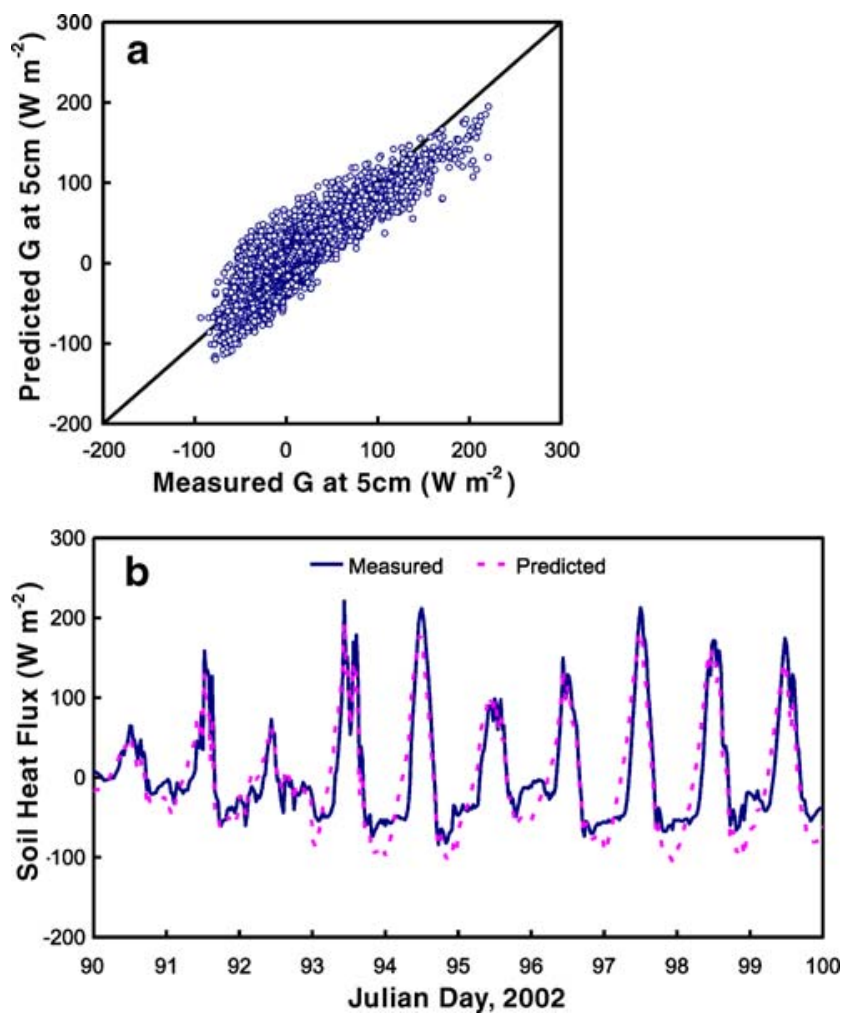

Fig. 4 Comparisons between observed and estimated soil heat fluxes calcualted by the traditional sinusoidal analytical method at the surface. a Scatter plot, b time series plot from days 90 to 100

ments and predictions from days 90 to 100 are plotted in Fig. $4 \mathrm{~b}$ (and the other time series plots in this study). Good agreement between $G_{\mathrm{m}}(0, t)$ and $G_{\mathrm{p}}(0, t)$ is found and the $R^{2}$ and SEE in Fig. $4 \mathrm{a}$ are 0.76 and $16.45\left(\mathrm{~W} \mathrm{~m}^{-2}\right)$, respectively. This demonstrates that the analytical method in conjunction with the soil heat storage term can reasonably capture the magnitude and temporal evolution of soil heat flux at the surface. This also reveals the importance of heat storage in determining the surface soil heat flux, $G(0, \mathrm{t})$. Figures $5 \mathrm{a}$ and $\mathrm{b}$ show comparisons between measured soil heat flux at $5 \mathrm{~cm}$ and heat storage in this $5 \mathrm{~cm}$ thickness of soil in scatter and time series plots, respectively. Note that the heat storage term is as large as the heat flux at this depth, and has similar temporal variation.

\section{Half-order time derivative method estimation}

With Eq. 10 and measured soil temperature at $5 \mathrm{~cm}$, we applied the half-order time derivative method (hereafter half-order method) to predict the soil heat flux at this depth. Figures $6 \mathrm{a}$ and $\mathrm{b}$ show comparisons between measured and predicted soil heat fluxes in scatter and time series plots, respectively. Notice that the half-order method predicted the soil heat flux very well, not only in magnitude but also in
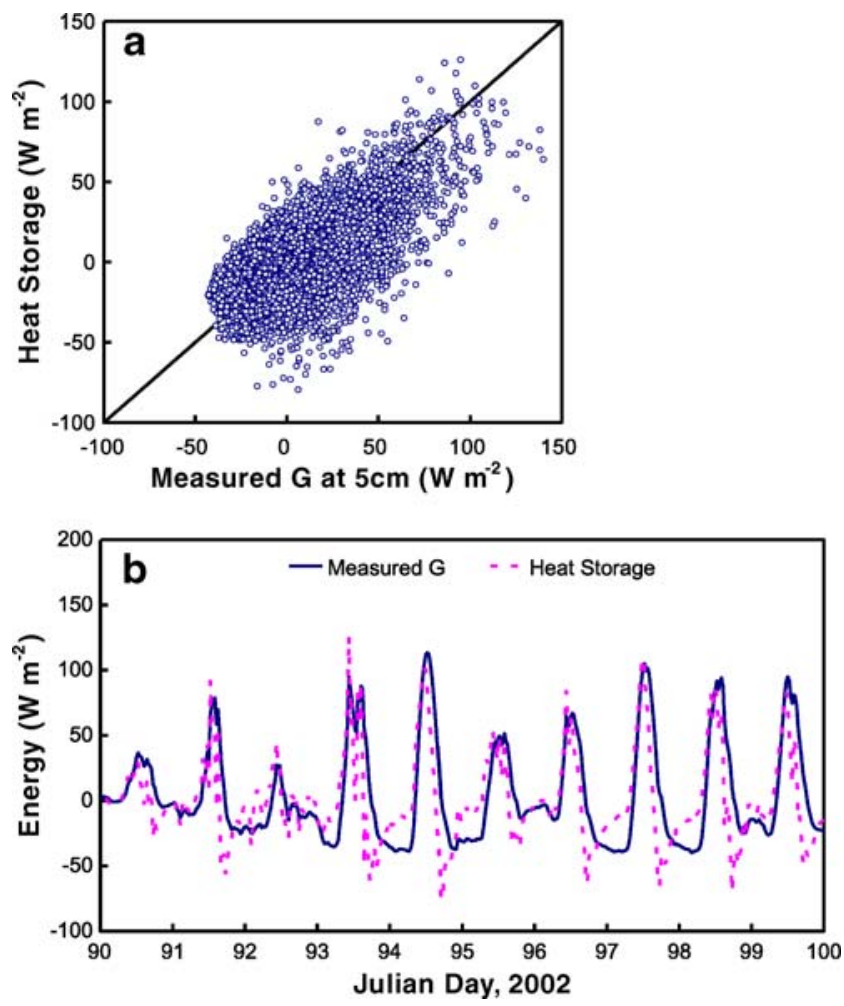

Fig. 5 Comparisons between observed soil heat fluxes at $5 \mathrm{~cm}$ and the heat storage. a Scatter plot, b time series plot from days 90 to 100
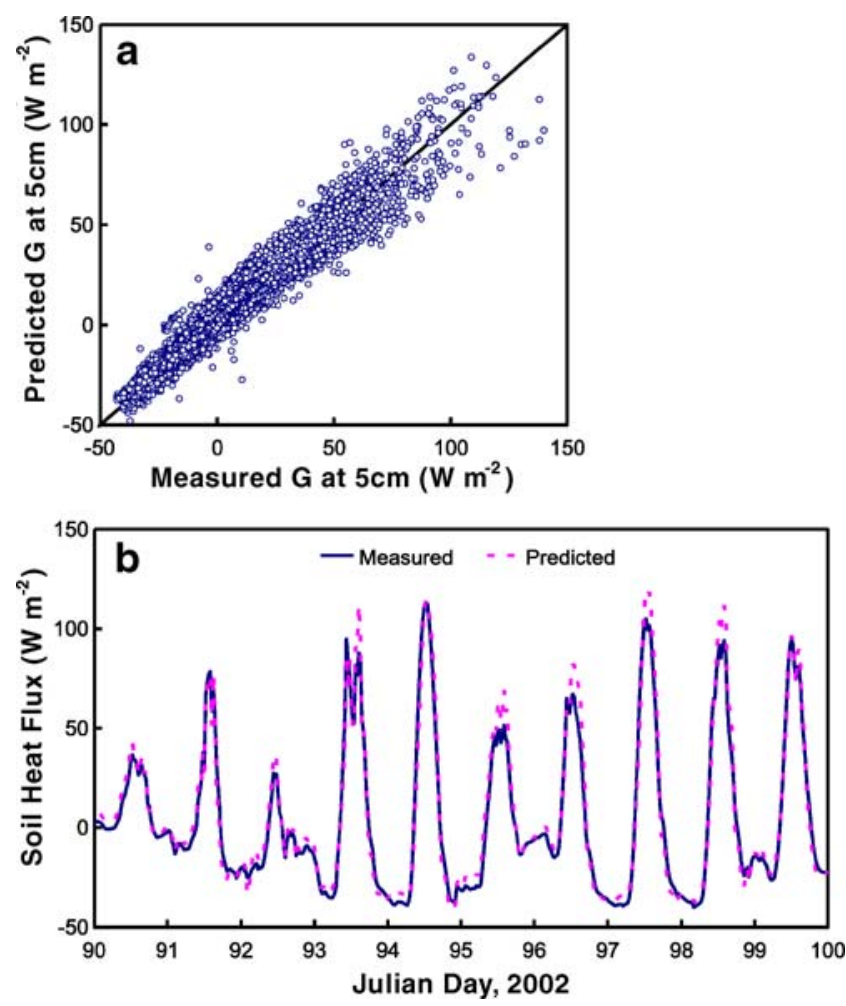

Fig. 6 Comparisons between observed and estimated soil heat flux by the half-order method at $5 \mathrm{~cm}$. a Scatter plot, b time series plot from says 90 to 100 
temporal trend. The $R^{2}$ and SEE in Fig. 6a are 0.94 and 5.4 $\left(\mathrm{W} \mathrm{m}^{-2}\right)$, respectively. As in Fig. 4a and b, we also used the half-order method to predict the soil heat flux at the surface, $G(0, t)$, and the results are shown in Fig. $7 \mathrm{a}$ and $\mathrm{b}$, respectively. Not surprisingly, good agreement was found in both figures. Figures $6 \mathrm{a}$ and $7 \mathrm{~b}$ demonstrate that the halforder method can capture the magnitude and temporal evolution of soil heat flux at the surface, and any other depth, well.

Not only the soil heat flux but also the soil temperature can be estimated using the half-order method. With similar derivation, as detailed in the Appendix, the soil temperature can be expressed as the integration of soil heat flux (Wang and Bras 1999):

$T(z, t)=T_{0}+\frac{1}{\sqrt{\pi k \rho_{s} c_{s}}} \int_{0}^{t} \frac{G(z, s) d s}{\sqrt{t-s}}$

Using Eq. 13 and measured soil heat flux at $5 \mathrm{~cm}$, Fig. 8a and $\mathrm{b}$ show the scatter and time series comparisons between measurements and predictions of soil temperature, respectively. It can be seen that this method can record the temporal trend of the soil temperature but not the magnitude. Figure $8 \mathrm{~b}$ reveals that when an error of temperature estimation occurs, it remains in the integration formula, Eq. 13, hence affecting the magnitude of the latter estimations.
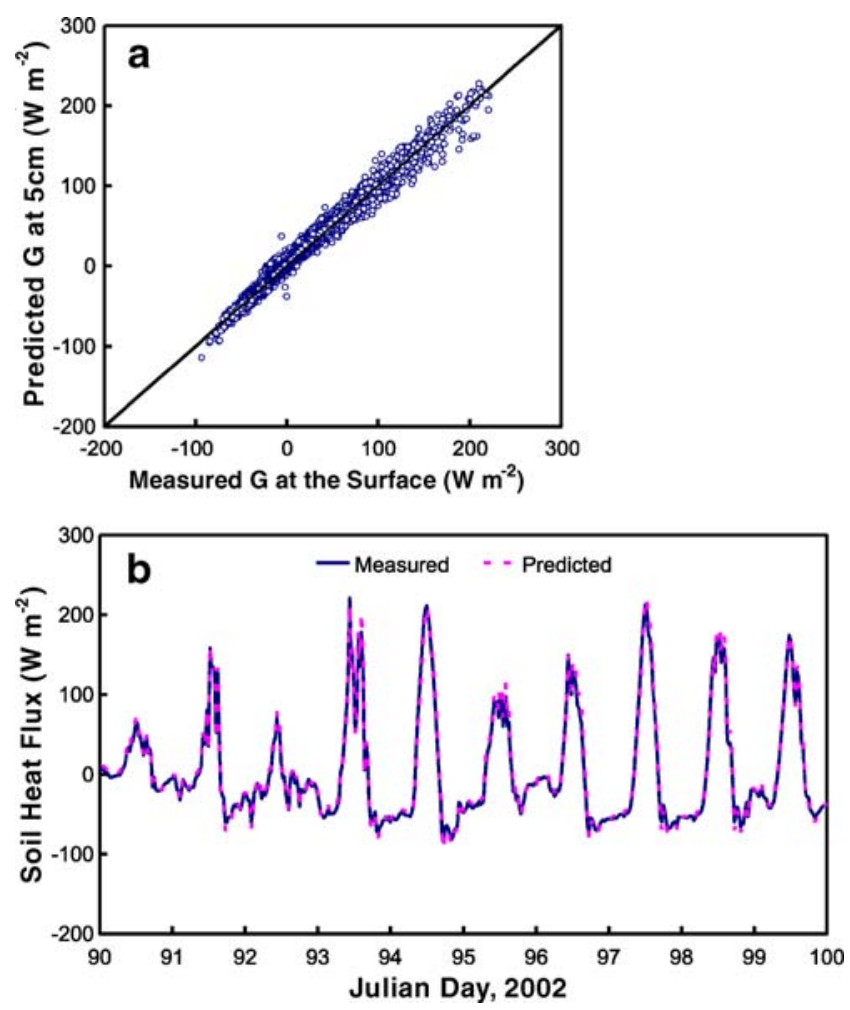

Fig. 7 Comparisons between observed and estimated soil heat flux by the half-order method at the surface. a Scatter plot, $\mathbf{b}$ time series plot from days 90 to 100
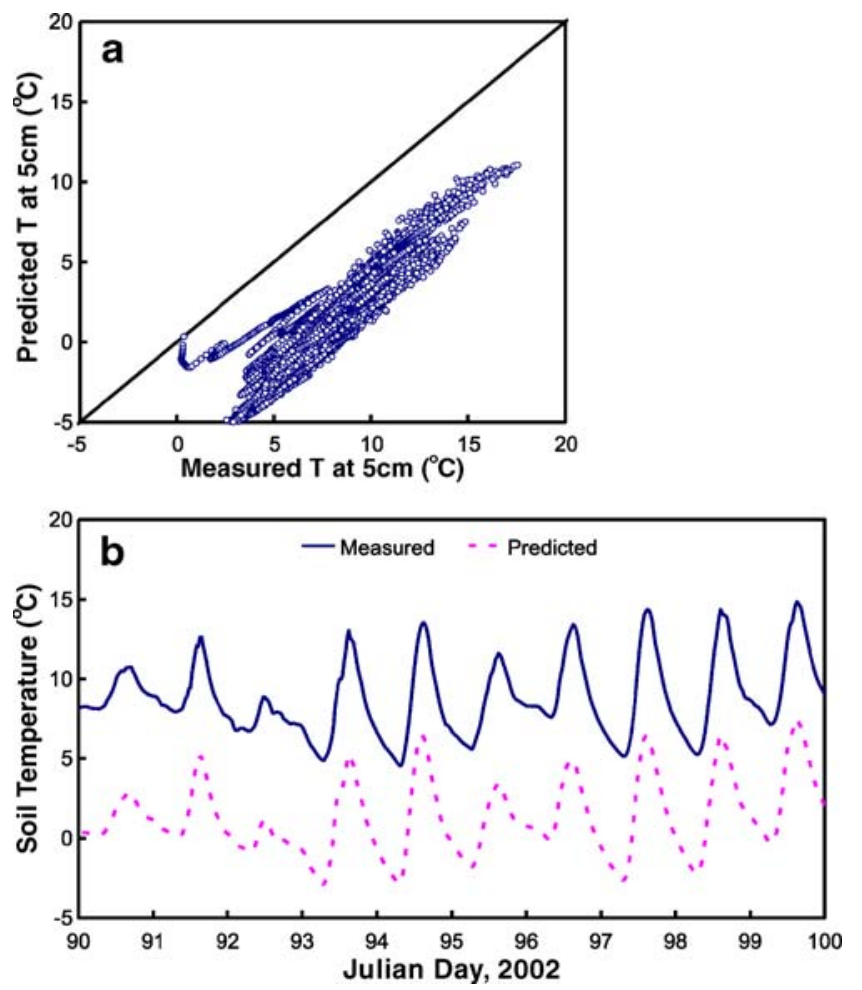

Fig. 8 Comparisons between observed and estimated soil temperature by the half-order method at $5 \mathrm{~cm}$. a Scatter plot, b time series plot from days 90 to 100

In Figure 8, estimations were obtained by Eq. 13 and the integration time period was 365 days $(t=365)$, i.e. the time integral in Eq. 13 was carried out continuously from day 1 (initial point) to day 365 . To further examine the performance of the half-order method for long-tem estimation of soil temperature, Eq. 13 was adopted with a different integration time period (cycle). Figure 9a shows the comparison between measured and predicted soil temperature by Eq. 13 with an integration time period (cycle) of 100 days, i.e. the time integral was carried out continuously from day 1 (first initial point) to day 101, and then a new integral was carried out from day 101 to 201 with a new and known initial temperature at day 101 (second initial point); this time integration was then repeated periodically with a cycle of 100 days until the end of day 365. Figures $9 \mathrm{~b}$ and $\mathrm{c}$ are the same as Fig. 9a but the integration time cycles were 10 days and 2 days, respectively. In Fig. 9a-c, the $R^{2}$ values are $0.85,0.90$, and 0.96 , respectively, and the SEE are $4.56,1.82$, and $1.0\left({ }^{\circ} \mathrm{C}\right)$, respectively (regression statistics are also summarised in Table 3 ). It is clear that the performance of the half-order method for estimating soil temperature depends on the integration time period (cycle): the shorter the integration period, the better the temperature estimation. This indicates that this method is less suitable for long-term (say longer than 100 days) estimation of soil temperature. Or, in other words, this method needs 

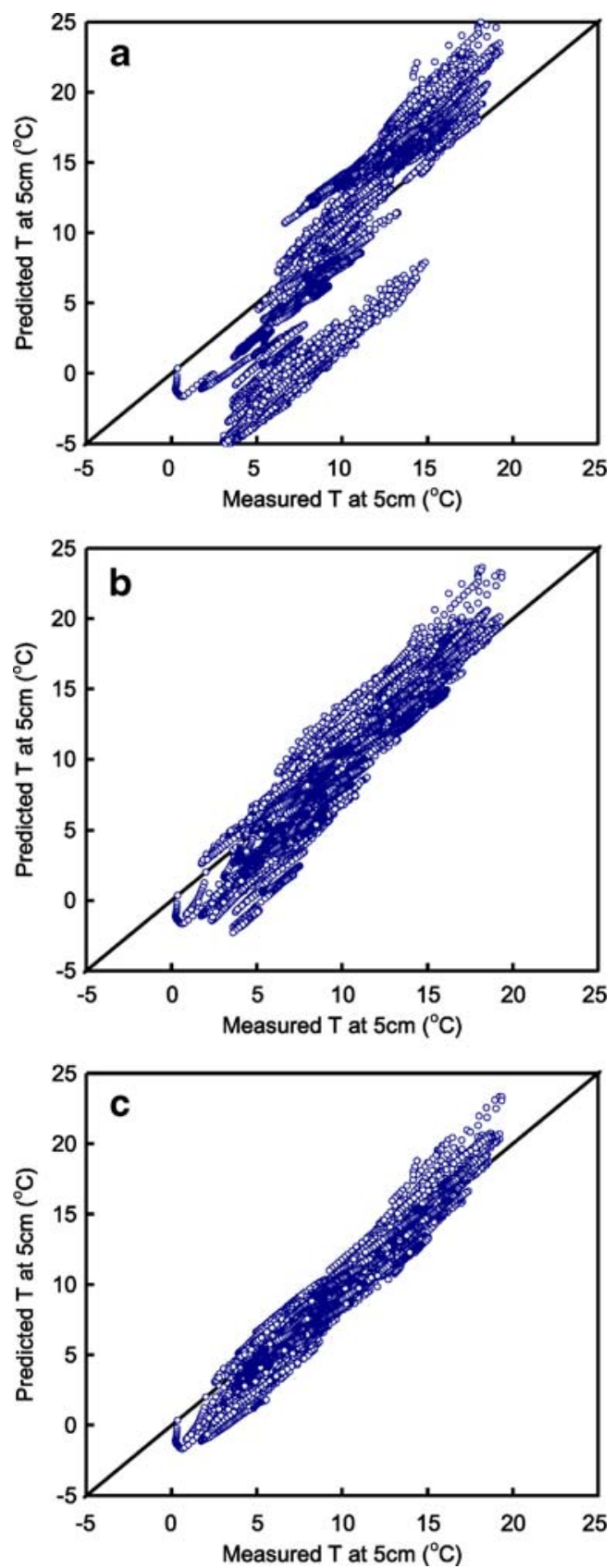

Fig. 9 Comparisons between observed and estimated soil temperature by the half-order method at $5 \mathrm{~cm}$ with different integral time cycles. a 100 days, b 10 days, $\mathbf{c} 2$ days

references (initial temperatures) periodically to prevent drift on temperature estimations when these estimations are inferred from a long history of observed heat flux data.

Now back to the prediction of soil heat flux. In Fig. 6, the flux estimations were obtained by Eq. 10 and the integration time period was 365 days (as in Fig. 8). To study the influence of the integration time period on the performance of the half-order method for predicting soil heat flux, Eq. 10 was adopted with a different integration time period (cycle). Figure 10a shows the comparison between measured and predicted soil heat flux calculated using Eq. 10 with an integration time period (cycle) of 100 days; Fig. 10b and c show integration time cycles of 10 days and 2 days, respectively. In Fig. $10 \mathrm{a}-\mathrm{c}$, the $R^{2}$ values are between 0.88 and 0.92 , and the SEE is between 7.1 and $5.5\left(\mathrm{~W} \mathrm{~m}^{-2}\right)$; detailed regression statistics are listed in Table 3. It can be seen that, unlike with the temperature estimations, the performance of this method for estimating
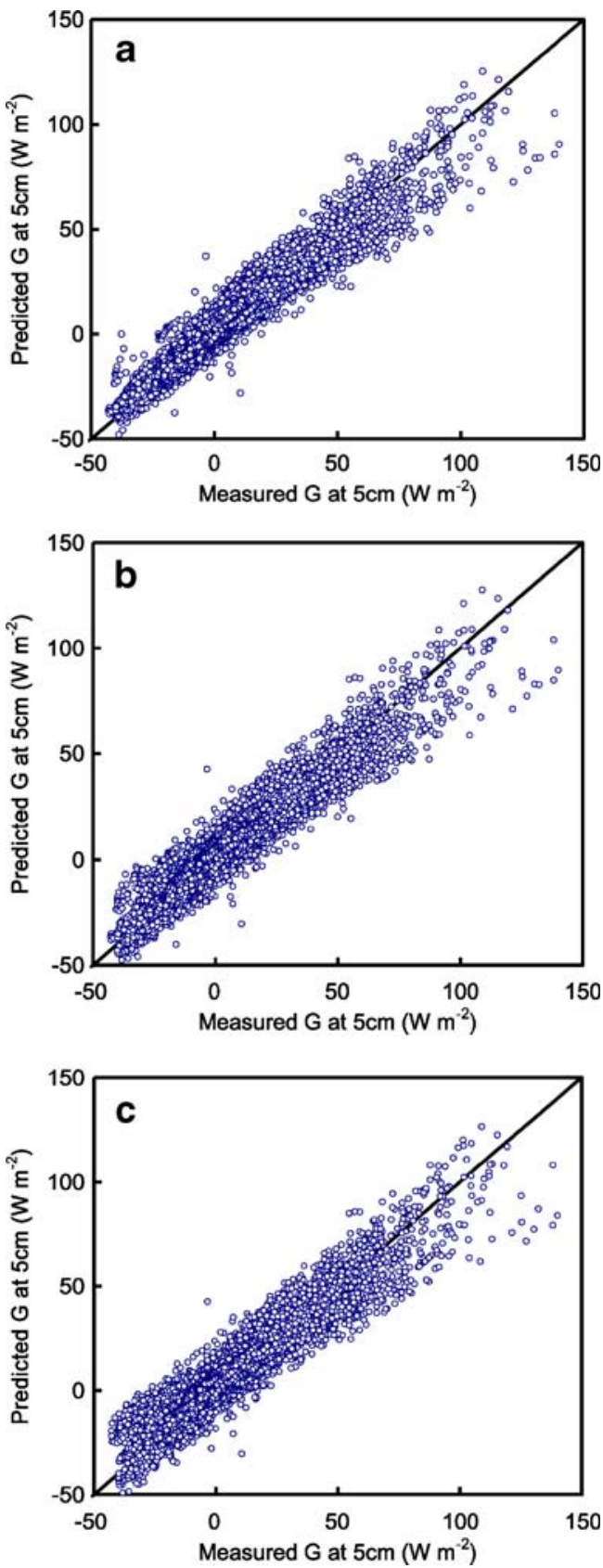

Fig. 10 Comparisons between observed and estimated soil heat fluxes calculated by the half-order method at $5 \mathrm{~cm}$ with different integral time cycles. a 100 days, b 10 days, c 2 days 
Table 3 Coefficients of regression analyses between measured and estimated soil temperature/heat fluxes calculated by the half-order time derivative method with different integration time cycles

\begin{tabular}{llllll}
\hline $\begin{array}{l}\text { Parameter } \\
\text { estimated }\end{array}$ & $\begin{array}{l}\text { Time } \\
\text { cycle }\end{array}$ & Slope & Intercept & $R^{2}$ & SEE \\
\hline Soil temperature & 100 days & 1.88 & -9.98 & 0.85 & 4.56 \\
& 10 days & 1.25 & -2.89 & 0.90 & 1.82 \\
& 2 days & 1.12 & -1.48 & 0.96 & 1.00 \\
Soil heat flux & 100 days & 0.91 & 0.92 & 0.92 & 5.52 \\
& 10 days & 0.90 & 0.91 & 0.90 & 6.23 \\
& 2 day & 0.88 & 1.47 & 0.88 & 7.05 \\
\hline
\end{tabular}

soil heat flux is less related to the integration time period (cycle). This demonstrates that the half-order method is suitable for both short-term and long-term estimations of soil heat flux. The reason that the soil temperature estimation is sensitive to the integration period but the soil heat flux is not is attributed to the following.

(1) In Eq. 10 (or its discrete form Eq. A19, see Appendix), the integral is taken with respect to the temperature gradient with time, $\partial \mathrm{T} / \partial \mathrm{t}$; hence the accuracy of Eqs. 10 or A19 does not depend on the temperature magnitude but the temperature fluctuation with time. If a drift in the temperature history occurs over a certain period, its influence on the integration process is attenuated by taking the temperature gradient.

(2) In Eq. 13, the integral is taken with respect to the soil heat flux, $G$; hence if a drift in soil heat flux magnitude occurs within some periods, its influence on the integration process stays there and will cause estimation errors.

\section{Conclusions}

In this study, we investigated the importance of soil heat flux at a temperate and humid grassland in Ireland and examine the performances of the traditional sinusoidal analytical method and the half-order time derivative method for long-term estimation of soil heat flux. The usefulness of adopting the half-order time derivative method for inferring soil temperature from soil heat flux was also presented. The common advantage of these two methods is that they need only one single-layer of soil temperature measurements in order to predict soil heat flux. Our results suggest the following:

(1) The soil heat flux at this temperate and humid grassland had the same magnitude as the sensible heat flux and accounted for $24 \%$ of the net radiation energy.

(2) The traditional sinusoidal analytical method did not reproduce the measured soil heat flux at $5 \mathrm{~cm}$ depth as the sinusoidal assumption was not valid. However, by adding the amount of heat storage in this depth of soil to the surface soil heat flux calculation, this analytical method could predict the soil heat flux at the surface well.

(3) The predicted soil heat fluxes at the surface and $5 \mathrm{~cm}$ depth by the half-order time derivative method were found to be in good agreement with measured values; the $R^{2}$ values were above 0.9 . This demonstrates the usefulness of this method for long-term prediction of soil heat flux from remotely sensed surface temperature.

(4) The half-order time derivative method was found to be less suitable for long-term estimation of soil temperature from soil heat flux data. However, if the reference temperatures (i.e. initial temperatures) at each integral period are known, then this method can reproduce the soil temperature well.

Acknowledgements The authors would like to thank the two anonymous reviewers for their helpful comments. C.-I.H. and C.-W.H. thank the National Science Council, Taiwan for their support of this study. G.K. acknowledges support from the ERTDI program managed by the Irish Environmental Protection Agency and funded by the Irish Government under the National Development Plan, 2000-2006 (CELTICFLUX, 2001-CC-C2-M1).

\section{Appendix: Derivation of the half-order time derivative method}

The algorithm and derivation of the half-order time derivative method was first proposed by Wang and Bras (1999). Here, details of the derivation are provided.

First of all, define two new variables: $\widetilde{z}=z / \sqrt{D_{0}}$ and $\Theta=T-T_{0}$, and then transfer Eqs. 7, 9, and 10 to:

$\frac{\partial \Theta}{\partial t}=\frac{\partial^{2} \Theta}{\partial \widetilde{z}^{2}}$

$\Theta=0$, for $\mathrm{t}=0, \widetilde{z}<0$

$\Theta=0$, for $\mathrm{t}>0, \widetilde{z} \rightarrow-\infty$

Now, take the Laplace transform of both sides of Eq. A1. According to the definition of Laplace transform, $L\left\{\frac{\partial}{\partial t} f(t)\right\}(s)=s F(s)-f(0)$, the left hand side of A1 then becomes $s \widetilde{\Theta}(\widetilde{z}, s)-\Theta(\widetilde{z}, 0)=s \widetilde{\Theta}(\widetilde{z}, s)$ since A2 requires $\Theta(\widetilde{z}, 0)=0$. The Laplace transform of the right hand side 
remains the same since the Laplace transform is based on the variable $t$. Hence, Eq. A1 is transformed to

$s \widetilde{\Theta}(\widetilde{z}, s)=\frac{\partial^{2} \widetilde{\Theta}}{\partial \widetilde{z}^{2}}$

where $\widetilde{\Theta}$ is the Laplace transform of $\Theta$ and defined as:

$\widetilde{\Theta}(\widetilde{z}, s)=\int_{0}^{\infty} \exp (-s t) \Theta(\widetilde{z}, t) d t$

The general solution of Eq. A4 is

$\widetilde{\Theta}(\widetilde{z}, s)=A(s) \exp (\widetilde{z} \sqrt{s})+B(s) \exp (-\widetilde{z} \sqrt{s})$

where $\mathrm{A}(\mathrm{s})$ and $\mathrm{B}(\mathrm{s})$ are arbitrary functions of $\mathrm{s}$ and can be determined by the boundary conditions. By Eq. A3, B(s) is found to be zero and Eq. A6 then becomes:

$\widetilde{\Theta}(\widetilde{z}, s)=A(s) \exp (\widetilde{z} \sqrt{s})$

Differentiating both sides of Eq. A7 with respect to $\widetilde{z}$ gives:

$\frac{\partial}{\partial \widetilde{z}} \widetilde{\Theta}(\widetilde{z}, s)=\sqrt{s} A(s) \exp (\widetilde{z} \sqrt{s})$

Now, substituting A7 into A8 yields

$\frac{\partial}{\partial \widetilde{z}} \widetilde{\Theta}(\widetilde{z}, s)=\sqrt{s} \widetilde{\Theta}(\widetilde{z}, s)$

Based on the equation derived by the fractional calculus (Miller and Ross 1993),

$L\left\{D^{v} f(t)\right\}=s^{v} F(s)-\sum_{k=0}^{m-1} s^{m-k-1} D^{k-m+v} f(0)$

the right hand side of Eq. A9 becomes

$\sqrt{s} \widetilde{\Theta}(\widetilde{z}, s)=L\left\{\frac{\partial^{\frac{1}{2}}}{\partial t^{\frac{1}{2}}} \widetilde{\Theta}(\widetilde{z}, t)\right\}$

By the initial condition Eq. A2, the last term of Eq. A10, $f(0)$, is found to be zero. Replacing the right hand side of Eq. A9 by Eq. A11, we have

$\frac{\partial}{\partial \widetilde{z}} \widetilde{\Theta}(\widetilde{z}, s)=L\left\{\frac{\partial^{\frac{1}{2}}}{\partial t^{\frac{1}{2}}} \widetilde{\Theta}(\widetilde{z}, t)\right\}$

Inverting the Laplace transform of Eq. A12 leads to

$\frac{\partial}{\partial \widetilde{z}} \Theta(\widetilde{z}, t)=\frac{\partial^{\frac{1}{2}}}{\partial t^{\frac{1}{2}}} \Theta(\widetilde{z}, t)$

With the definition of $\Theta$, Eq. A13 becomes

$\frac{\partial}{\partial z} T(z, t)=\frac{1}{\sqrt{D_{o}}} \frac{\partial^{\frac{1}{2}}}{\partial t^{\frac{1}{2}}}[T(z, t)-T(0)]$.
Now, applying the fractional calculus (Miller and Ross 1993)

$\frac{d^{\alpha} f(t)}{d t^{\alpha}}=\frac{1}{\Gamma(1-\alpha)} \frac{d}{d t} \int_{0}^{t} \frac{f(s)}{(t-s)^{\alpha}} d s$

to the right hand side of Eq. A14, we have

$$
\frac{\partial}{\partial z} T(z, t)=\frac{1}{\sqrt{\pi D_{0}}} \int_{0}^{t} \frac{\partial T(z, s)}{\partial s} \frac{d s}{\sqrt{t-s}}=\frac{1}{\sqrt{\pi D_{0}}} \int_{0}^{t} \frac{d T(z, s)}{\sqrt{t-s}}
$$

Finally, the prognostic result can be evaluated by applying Eq. A16 to Fourier's law, and then we have

$G(z, t)=\sqrt{\frac{k \rho_{s} c_{s}}{\pi}} \int_{0}^{t} \frac{d T(z, s)}{\sqrt{t-s}}$

Equation A17 can also be written as:

$$
\begin{aligned}
G(z, t) & =\sqrt{\frac{k \rho_{s} c_{s}}{\pi}} \int_{0}^{t} \frac{\partial T(z, s)}{\partial s} \frac{d s}{\sqrt{t-s}} \\
& =2 \sqrt{\frac{k \rho_{s} c_{s}}{\pi}} \int_{0}^{t} \frac{\partial T(z, s)}{\partial s} d \sqrt{t-s}
\end{aligned}
$$

And its discrete form is

$$
\begin{aligned}
G= & 2 \sqrt{\frac{k \rho_{s} c_{s}}{\pi}} \\
& \times \sum_{i=0}^{N} \frac{T_{i+1}-T_{i}}{t_{i+1}-t_{i}}\left[\sqrt{t_{N}-t_{i+1}}-\sqrt{t_{N}-t_{i}}\right]
\end{aligned}
$$

where $N$ is the number of intervals.

\section{References}

Campbell GS, Norman JM (1998) An introduction to environmental biophysics. Bartlett, Marietta, GA, p 286

Carslaw HS, Jaeger JC (1986) Conduction of heat in solids. Clarendon, Oxford, p 510

Clothier BE, Clawson KL, Pinter PJ Jr., Moran MS, Reginato RJ, Jackson RD (1986) Estimation of soil heat flux from radiation during the growth of alfalfa. Agric For Meteorol 37:319-329

Idso SB, Aase JK, Jackson RD (1975) Net radiation-soil heat flux relations as influenced by water content variations. Boundary Layer Meteorol 9:113-122

Kimball BA, Jackson RD (1975) Soil heat-flux determination: a nullalignment method. Agric For Meteorol 15:1-9

Kustas WP, Daughtry CST (1990) Estimation of the soil heat flux/net radiation ratio from spectral data. Agric For Meteorol 49:205-223 
Malek E (1993) Rapid changes of the surface soil heat flux and its effects on the estimation of evapo-transpiration. J Hydrol 142:89-97

Miller KS, Ross B (1993) An introduction to the fractional calculus and fractional differential equations. Wiley, New York

Ogee J, Lamaud E, Brunet Y Berbigier P, Bonnefond JM (2001) A long-term study of soil heat flux under a forest canopy. Agric For Meteorol 106:173-186
Stull RB (1988) An introduction to boundary layer meteorology. Kluwer, Dordrecht, p 666

Wang J, Bras RL (1999) Ground heat flux estimated from surface soil temperature. J Hydrol 216:214-226

Zhang HF, Ge XS, Ye H, Jiao DS (2007) Heat conduction and heat storage characteristics of soils. Appl Thermal Eng 27: 369-373 